\title{
Modulating pyrimidine ribonucleotide levels for the treatment of cancer
}

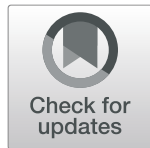

Tanzina Mollick ${ }^{1,2}$ and Sonia Laín ${ }^{1,2^{*}}$ (D)

\begin{abstract}
By providing the necessary building blocks for nucleic acids and precursors for cell membrane synthesis, pyrimidine ribonucleotides are essential for cell growth and proliferation. Therefore, depleting pyrimidine ribonucleotide pools has long been considered as a strategy to reduce cancer cell growth. Here, we review the pharmacological approaches that have been employed to modulate pyrimidine ribonucleotide synthesis and degradation routes and discuss their potential use in cancer therapy. New developments in the treatment of myeloid malignancies with inhibitors of pyrimidine ribonucleotide synthesis justify revisiting the literature as well as discussing whether targeting this metabolic pathway can be effective and sufficiently selective for cancer cells to warrant an acceptable therapeutic index in patients.
\end{abstract}

Keywords: Pyrimidine ribonucleotide metabolism, Cancer therapy, CAD, DHODH, UMPS, Nucleoside transporters, CDA, CTPS, Therapeutic index

\section{Background}

Pyrimidine ribonucleotides are involved in multiple cellular processes that maintain cell growth and metabolism [1]. Aside from being the building blocks of RNA and precursors for deoxyribonucleotides, pyrimidine ribonucleotides are necessary for glycogen and cell membrane precursor synthesis, glycosylation of proteins and lipids, and in detoxification processes like glucuronidation [1-4]. In addition, uracil nucleotides can interact with $G$ proteincoupled nucleotide receptors to activate the phosphatidylinositol-calcium second messenger system $[5,6]$, and cCMP as well as cUMP can themselves act as second messengers $[7,8]$.

The activity of enzymes involved in pyrimidine ribonucleotide synthesis is required for cellular proliferation [9-14], and it has been observed that many tumors show upregulation of these enzymes [15-20]. Thus, depleting

\footnotetext{
* Correspondence: sonia.lain@ki.se

${ }^{1}$ Department of Microbiology, Tumor and Cell Biology, Karolinska Institutet, Solnavägen 9, SE-171 65, Solna, Stockholm, Sweden

${ }^{2}$ SciLifeLab, Department of Microbiology, Tumor and Cell Biology, Karolinska Institutet, Tomtebodavägen 23, SE-171 65, Solna, Stockholm, Sweden
}

pyrimidine ribonucleotide pools has long been considered an option for cancer treatment. In light of this, a number of inhibitors of enzymes of the pyrimidine ribonucleotide synthesis pathway have been developed in the past decades. However, due to unsatisfactory results in the clinic, further work in this line of therapy was not given priority [21-31]. It was not until recently that new insights have once again drawn attention towards pyrimidine metabolism [32-34]. In this review, we focus on the enzymes in the pyrimidine synthesis and degradation pathways for which small molecule inhibitors are available and either considered or evaluated in clinical trials.

\section{Pyrimidine ribonucleotide synthesis}

Cellular pyrimidine ribonucleotide pools are maintained through the de novo synthesis and salvage pathways [1, 4] (Fig. 1). The relative importance of these pathways depends on the cell type and its physiological state. It has been suggested that rapidly proliferating cells, whether normal (e.g., activated $\mathrm{T}$ cells) or cancerous, depend on the de novo pyrimidine pathway, whereas differentiated cells, having

C The Author(s). 2020 Open Access This article is licensed under a Creative Commons Attribution 4.0 International License, which permits use, sharing, adaptation, distribution and reproduction in any medium or format, as long as you give appropriate credit to the original author(s) and the source, provide a link to the Creative Commons licence, and indicate if changes were made. The images or other third party material in this article are included in the article's Creative Commons licence, unless indicated otherwise in a credit line to the material. If material is not included in the article's Creative Commons licence and your intended use is not permitted by statutory regulation or exceeds the permitted use, you will need to obtain permission directly from the copyright holder. To view a copy of this licence, visit http://creativecommons.org/licenses/by/4.0/ The Creative Commons Public Domain Dedication waiver (http://creativecommons.org/publicdomain/zero/1.0/) applies to the data made available in this article, unless otherwise stated in a credit line to the data. 


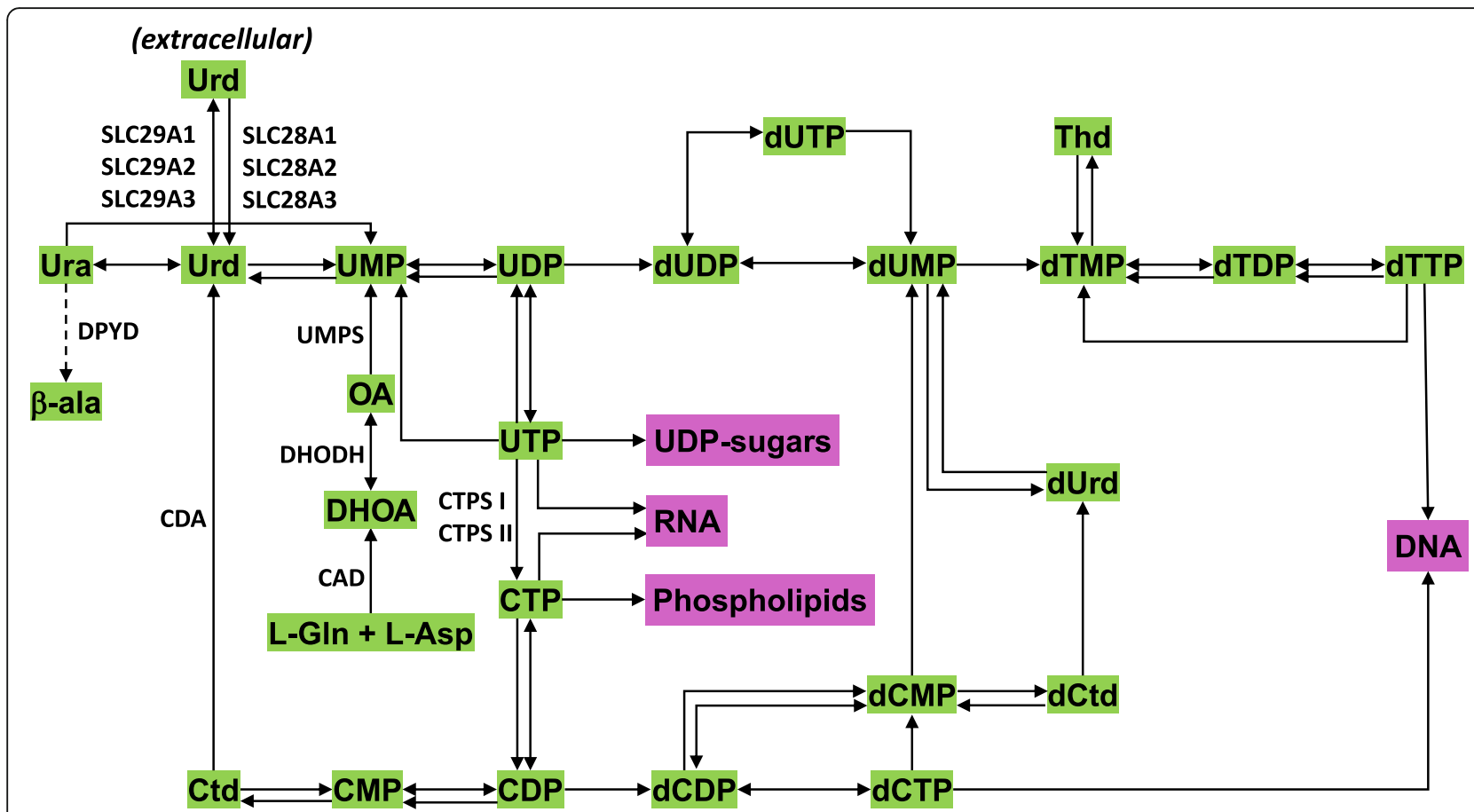

Fig. 1 Simplified schematic of pyrimidine nucleotide synthesis showing enzymes targeted for cancer therapy. For details, see the KEGG pathway, and for abbreviations, refer to the list

lower demands, usually rely on the less energy requiring pyrimidine salvage pathway [1].

\section{The de novo pyrimidine ribonucleotide synthesis pathway}

In the de novo synthesis pathway, the pyrimidine ring structure is assembled through a multistep pathway with L-glutamine and L-aspartate as precursors $[1,2,4]$. Whereas L-aspartate is a non-essential amino acid, L-glutamine is designated as a conditionally essential amino acid that becomes vital during periods of rapid growth or disease [35]. These two precursors are transformed into dihydroorotate by the three activities of the multifunctional enzyme CAD (carbamoylphosphate synthetase II, aspartate transcarbamoylase, and dihydroorotase). Next, orotate is formed by the action of dihydroorotate dehydrogenase (DHODH). DHODH is the only enzyme in the pathway located in mitochondria. DHODH catalyzes the oxidation of dihydroorotate to orotate using ubiquinone as an electron acceptor. Therefore, DHODH is dependent on and contributes to the activity of the mitochondrial electron transport chain $[1,2,4]$. The third enzyme of the de novo synthesis pathway is the bifunctional uridine monophosphate synthetase (UMPS) which catalyzes the formation of the first ribonucleotide product uridine $5^{\prime}$ monophosphate (UMP) through the action of its orotate phosphoribosyltransferase and orotidine-5'-monophosphate decarboxylase activities.
Once UMP is formed, further steps in the anabolic pathway result in the formation of uridine $5^{\prime}$ diphosphate (UDP) and uridine $5^{\prime}$-triphosphate (UTP). UTP can be used for protein glycosylation and glycogen synthesis through the formation of UDP-linked sugars. It is also the precursor for cytidine 5 '-triphosphate (CTP) through the action of CTP synthetases I and II (CTPS I and II) [1, 4, 36, 37]. Most importantly, this is the only path to obtain cytosine nucleotides de novo in mammals. Aside from being a building block in RNA, CTP can be converted to cytidine 5'-diphosphate (CDP), which in turn can be transformed into deoxyCDP (dCDP) by ribonucleotide reductase (RNR) to provide building blocks for DNA. CTP is also essential for membrane formation, which relies on CDPlinked phospholipid precursors [37, 38].

Like CDP, UDP can be converted into dUDP by RNR. In turn, dUDP can be dephosphorylated into dUMP, a precursor for dTTP (2'-deoxythymidine- 5 '-triphosphate), and used for DNA synthesis. dUMP can also be phosphorylated into dUTP and incorporate in DNA, causing activation of the DNA damage response [39]. Excessive repair events can increase the risk of DNA fragmentation and cause cell death or genomic instability. Therefore, an excess of dUTP might contribute to the appearance of mutations that arise randomly during DNA replication [40]. 


\section{Salvage pathways}

A fundamental difference between purine and pyrimidine ribonucleotide salvage pathways is that purine ribonucleotides are recycled from their bases whereas pyrimidine ribonucleotides are mainly salvaged from their nucleosides [36]. Accordingly, in patients with deficient de novo pyrimidine ribonucleotide synthesis, uridine (but not uracil) is able to overcome pathological manifestations [41]. The precursors in the salvage pathway include intracellular uridine and cytidine as well as pyrimidine nucleosides from extracellular fluids [3]. In addition, it can be envisaged that pyrimidine ribonucleotides can be recycled from UDP-linked sugars, CDP-linked phospholipid precursors, pyrimidine deoxyribonucleotides, and RNA.

Most of the data on pyrimidine ribonucleoside/ribonucleotide levels in the Human Metabolome Database is derived from a review written in 1994 [3]. In a more recent study on plasma from healthy individuals [42], the following average values were obtained: cytidine $(0.25 \mu \mathrm{M})$, uracil $(2.10 \mu \mathrm{M})$, uridine $(3.12 \mu \mathrm{M})$, and orotate $(0.89 \mu \mathrm{M})$. Cytosine was below the detection limit of the method. Strikingly, there are no enzymes that can lead to or process free cytosine in mammals (see KEGG pathways). One potential difference between mice and humans is the concentration of cytidine in plasma. According to the current data [3], cytidine levels in the plasma of rodents are higher than in human plasma. It is likely that this feature may cause differences between mice and humans in response to drugs affecting ribonucleotide pools.

\section{Pyrimidine nucleoside/nucleobase transporters}

Extracellular uridine is imported into cells by two classes of pyrimidine and purine nucleoside/nucleobase transporters: equilibrative and concentrative [43, 44]. These transporters are also involved in the uptake of anticancer nucleoside analogues such as cytarabine and gemcitabine [45]. Furthermore, single nucleotide polymorphisms in drug transporters may contribute to variations between individuals in response to nucleoside drugs $[46,47]$.

Equilibrative nucleoside transporters (ENT1, ENT2, ENT3, and ENT4, also known as SLC29A1, SLC29A2, SLC29A3, and SLC29A4) are bidirectional sodiumindependent transporters [43, 44, 47, 48]. Human ENT1 and ENT2 transport purine and pyrimidine nucleosides, while ENT2 and ENT3 also transport nucleobases $[43,48]$. ENT4 is uniquely selective for adenosine and a variety of organic cations, despite its structural similarity with other ENTs [49]. With regard to cellular localization, ENT1, ENT2, and ENT4 are primarily located in the cytoplasmic membrane. However, ENT1 and ENT2 can additionally be found in the nuclear membranes and, in case of ENT2, also in the mitochondrial membrane. ENT3 only appears to function in intracellular membranes including those of the lysosomes and mitochondria [43]. Concentrative nucleoside transporters (CNT1, CNT2, and CNT3, also known as SLC28A1, SLC28A2, and SLC28A3) are unidirectional sodium-dependent active transporters that have higher affinity for uridine than ENTs $[43,48,50]$ but a lower turnover rate of transport $[43,51]$. Although all the CNTs transport uridine, CNT1 preferentially transports pyrimidine nucleosides, CNT2 purine nucleosides, and CNT3 both pyrimidine and purine nucleosides [43, 48]. CNT1-3 are primarily located in the cytoplasmic membrane, but CNT3 is additionally present in subcellular membranes of specific cell types [43]. Both ENTs and CNTs participate in maintaining uridine (as well as other nucleoside and nucleobase) homeostasis through their activities in the intestine, liver, and kidneys [43, 50].

\section{Modulation of uridine plasma levels}

Uridine plasma levels should be taken into consideration when assessing the response to drugs lowering pyrimidine ribonucleotide pools. It is generally accepted that the liver plays a central role in maintaining plasma uridine by synthesizing and degrading uridine [36]. In addition, blood platelets contain high levels of UTP and may constitute another source of uridine [52]. Erythrocytes, which can rapidly take up orotate and convert it to UDP-glucose, are also thought to play an important role as uridine reservoirs [53]. In fact, uridine and glucose can be supplied to the brain, skeletal muscles, and peripheral tissues by the catabolism of erythrocyte UDP-glucose [36]. A recent study on mice, rats, and humans reported that fasting increases plasma uridine through a mechanism that involves uridine biosynthesis by adipocytes, whereas, in the postprandial state, liverinduced bile excretion results in plasma uridine clearance [54]. In support of this study, longer starvation times in human volunteers led to even more prominent increases in uridine plasma levels that were accompanied by a smaller rise in plasma cytidine and CTP [55]. Further confirmation came from a study where uridine as well as uracil and dihydrouracil levels in human plasma were observed to drop after food intake [56] and were also seen to be affected by circadian rhythms [56, 57]. In agreement with these observations, it has been seen that the oral bioavailability of uridine is low (5.8-9.9\%), due to poor absorption through the gastrointestinal mucosa [58]. Efforts at increasing the oral bioavailability of uridine led to the discovery of a prodrug, PN-401, which allowed sustained plasma levels of $>50 \mu \mathrm{M}$ 
[59]. Altogether, these studies may suggest that drugs lowering de novo pyrimidine ribonucleotide synthesis may be more effective when given after meals.

On a different note, an interesting study by Steculorum et al. may show a possible link as to how uridine plasma levels may affect feeding patterns [60]. They reported that high UDP levels in the hypothalamus were related to increased feeding behavior in mice through the activation of P2Y6 purinergic receptors in the agouti-related peptide neurons. Moreover, increasing plasma uridine levels, through intraperitoneal injection, promoted this activity by the increased synthesis of UDP in the brain. Interestingly, in metabolic disorders like obesity and type 2 diabetes mellitus, high uridine levels are sustained in the plasma which in turn affects food intake behavior due to high UDP levels in the brain [60]. This could indicate that the efficacy of inhibitors of de novo pyrimidine ribonucleotide synthesis may be affected in comorbid conditions that include such metabolic disorders.

\section{Pyrimidine ribonucleotide degradation}

Based on the pyrimidine metabolic pathway provided in the Kyoto Encyclopedia of Genes and Genomes database (KEGG pathway), UMP degradation occurs through the action of $5^{\prime}$-nucleotidases and uridine phosphorylases 1 and 2, which transform UMP into uridine and uridine into uracil, respectively. Uracil is finally transformed into $\beta$-alanine by the action of the enzymes dihydropyrimidine dehydrogenase (DPYD), dihydropyrimidinase, and $\beta$-ureidopropionase. This last enzyme leads to the synthesis of $\beta$-alanine through an irreversible reaction.

In humans, cytidine $5^{\prime}$-monophosphate (CMP) can only be transformed into cytidine but not to cytosine. Cytidine can only be converted into uridine by cytidine deaminase (CDA). dCMP and dUMP can both be converted into uracil whereas dTMP, after its conversion into thymidine and thymine, enters valine, leucine, and isoleucine metabolism (see the KEGG PATHWAY Database-GenomeNet).

Differences in the activity of the enzymes involved in pyrimidine ribonucleotide degradation are essential to predict 5-fluorouracil, gemcitabine, and cytarabine toxicity in cancer patients. These differences may be due to single nucleotide polymorphisms (SNPs) in CDA [61, 62] or DPYD [63] and, as shown for DPYD, related to food intake [56].

\section{Regulation of pyrimidine ribonucleotide synthesis enzymes: CAD}

Studies on the regulation of pyrimidine ribonucleotide synthesis are available only for a few of the enzymes in the pathway and mainly refer to the trifunctional enzyme
CAD, the first enzyme in the de novo pathway [37, 64]. Below, we discuss the key known factors involved in the regulation of CAD, many of which can be overactive in cancers. The reason we summarize these studies here is because pharmacologic modulation of these factors should affect $\mathrm{CAD}$ and therefore pyrimidine ribonucleotide synthesis.

\section{Regulation of enzyme expression}

The promoter of the CAD gene has E-box sequences for c-myc binding, and c-myc clearly increases CAD expression $[65,66]$. Furthermore, of the three enzymes in the de novo UMP synthesis pathway, CAD is the one that is more frequently overexpressed in tumors (FireBrowse database). DHODH as well as CTPS and enzymes of the purine synthesis pathway are also increased upon c-myc expression in Burkitt lymphoma cells [67]. Estrogen receptor/Sp1 complexes are also positive modulators of CAD transcription [68] whereas HIF1 $\alpha$ negatively regulates CAD expression [69].

\section{Allosteric regulation}

The carbamoylphosphate synthetase II (CPSII) domain of CAD is allosterically activated by ATP and phosphoribosyl pyrophosphate (PRPP) as well as inhibited by uracil and cytosine nucleosides UMP, UDP, UTP, CTP, and UDP-glucose [37, 70-72]. The activation of CAD (as well as of UMPS) by PRPP provides a link between the purine and pyrimidine synthesis pathways [37, 70-72].

\section{Post-translational modifications}

CAD regulation can also be mediated through phosphorylation by the mitogen-activated protein kinase cascade (MAPK, also referred to as Ras-Raf-MEK-ERK cascade) and cyclic adenosine monophosphatedependent protein kinase (PKA) cascades $[37,73]$. It has been demonstrated, both in vitro and in vivo, that in the presence of a growth stimulus, ERK2 phosphorylates CAD at Thr456 and also alters the allosteric regulation of CAD, whereby its activation by PRPP is promoted and feedback inhibition by UTP is suppressed [37, 73, 74]. The MAPK-mediated activation of CAD can be antagonized by PKA phosphorylation of its serine residue at 1406. This leads to the reversal of the sensitivity of CAD to PRPP and UTP, consequently downregulating ribonucleotide synthesis $[73,75,76]$. The sequential coordination of MAPK and PKA phosphorylation of CAD has been closely associated with the cell cycle [73, 77]. MAPK phosphorylation of CAD occurs in cells entering early $\mathrm{S}$ phase, when the need for pyrimidine ribonucleotides is greatest, whereas PKA phosphorylation predominates at late $S$ phase [77]. In addition, it has been reported that phosphorylation of CAD at Ser1873 by 
protein kinase $\mathrm{C}$ (PKC) may precede activation of $\mathrm{CAD}$ by the MAPK cascade [78].

It is not surprising that cancer cells would take advantage of these regulatory mechanisms to increase cell proliferation. For example, in the MCF7 breast cancer cell line, pyrimidine ribonucleotide synthesis goes unchecked due to $\mathrm{CAD}$ overexpression together with continuous phosphorylation at the MAPK site and absence of phosphorylation at the PKA site [79]. The MAPK pathway is frequently dysregulated in cancer due to mutations or amplifications in the upstream components of the pathway, which eventually lead to ERK hyperactivity [80-83]. Thus, targeting the pyrimidine ribonucleotide synthesis pathway may at least in part weaken the tumor promoting effect of alterations in the MAPK cascade.

Another protein kinase that has been shown to regulate $\mathrm{CAD}$ is mechanistic (or mammalian) target of rapamycin complex 1 (mTORC1) [84, 85]. mTORC1 is one of the two catalytic subunits of mTOR, a key kinase in balancing anabolic and catabolic processes to promote cell growth by stimulating glutamine metabolism and blocking autophagy [86]. It can also promote protein synthesis and enhance lipid synthesis, and there is emerging evidence linking mTORC1 activity to nucleotide metabolism [84, 85, 87, 88]. In 2013, phosphoproteomics and metabolomics profiling studies revealed that mTORC1 could stimulate pyrimidine ribonucleotide synthesis through activation of its downstream target S6 kinase 1, a kinase that phosphorylates the Ser1859 residue in CAD [84, 85] and activates the dihydroorotase domain of CAD [85]. Furthermore, phosphorylation at the Ser1859 site results in the oligomerization of CAD and enables steric channeling of substrates [84]. Interestingly, an upstream effector of mTORC1, Rheb, which is a small GTPase that belongs to the RAS superfamily, has also been shown to directly bind to CAD and regulate its activity [89].

mTORC1 signaling occurs downstream of the MAPK cascade and the phosphoinositide 3-kinase (PI3K)/AKT pathway. These pathways converge at mTORC1 by phosphorylating and inhibiting tuberous sclerosis complex 2 (TSC2), which is a negative regulator of mTORC1 $[87,88,90]$. Any mutation or amplification of the upstream effectors of mTORC1 or loss of function of the tumor suppressors that inhibit mTORC1, like TSC2, could lead to overstimulation of mTORC1 and drive tumor progression $[86,90,91]$. In fact, a majority of human tumors have been shown to possess mTORC1 hyperactivity and this has led to an increased interest in the development of more effective inhibitors than rapamycin [92]. However, mTORC1 inhibitors have shown unpredictable side effects in the clinic [93]. Furthermore, mutations of mTOR and activation of alternate proliferation pathways have been observed in response to
mTORC1 inhibitors [86]. As mentioned above for MAPK inhibitors, perhaps, inhibitors of the pyrimidine ribonucleotide synthesis pathway may at least partially contribute to eliminate mTORC1 inhibitor-resistant clones.

\section{Targeting enzymes involved in pyrimidine ribonucleotide metabolism for the treatment of cancer}

One important aspect to consider in any therapeutic approach is genotoxicity. And an important safety issue that needs to be addressed when using agents that deplete ribonucleotide pools is whether they harm the genome, and if they do whether this DNA damage is limited to cancer cells. In 1996, the group of Geoffrey Wahl [94] reported that inhibition of de novo ribonucleotide synthesis has different consequences depending on p53 status and that normal cells primarily respond by arresting in the G1 phase of the cell cycle. One interpretation of these results is that in normal cells, which have fully functional cell cycle checkpoints, a reduction in ribonucleotide levels could act as a warning signal that activates the cell cycle arresting function of p53 rather than its proapoptotic function. An arrest in G1 can be reversible, and therefore, normal cells may recover from ribonucleotide depletion. Thus, it is possible that inhibiting ribonucleotide synthesis is non-genotoxic to normal cells and causes reversible cell cycle arrest. Whether this holds true for highly proliferating cells such as activated $T$ cells needs to be investigated further. Indeed, inhibitors of pyrimidine ribonucleotide synthesis such as leflunomide are used as immunosuppressants $[95,96]$. This is of importance in the context of cancer as it may debilitate the anti-oncogenic effects of the immune system.

Cancer cells frequently have defective G1/S checkpoints and are therefore less likely to arrest in G1 than normal cells upon stress. If cells enter $S$ phase without sufficient nucleotide pools, stalled replication forks may appear, ultimately leading to extensive DNA damage. Whether this leads to cell death may depend on the presence of intact TP53. For cancer cells that retain wild-type p53, there is evidence suggesting that they will accumulate in $\mathrm{S}$ phase with high levels of active p53 and rapidly die [33]. Activation of p53 may be more likely to promote cell death in $\mathrm{S}$ phase cells than in cells in G1 (see below). Cancer cells defective for p53 may also accumulate in $\mathrm{S}$ phase upon ribonucleotide depletion and subsequent deoxyribonucleotide pool depletion, but what happens to these cells at this vulnerable stage is still unclear. In the case of p53-deficient acute myeloid leukemia cells for example, inhibition of the 
pyrimidine ribonucleotide de novo synthesis enzyme DHODH has been shown to cause differentiation and death [97].

Altogether, it is possible that inhibitors of pyrimidine ribonucleotide synthesis may help to control cancer progression without causing irreparable damage to normal tissue. Whether efficacy will be reached in the clinic is still an open question that will hopefully be answered soon by ongoing clinical trials. Below, we focus on efforts to modulate the function of enzymes and transporters involved in pyrimidine ribonucleotide metabolism and discuss their potential for cancer therapy.

\section{CAD inhibitors}

PALA ( $N$-phosphonacetyl-L-aspartate), an inhibitor of the aspartate transcarbamoylase activity of $\mathrm{CAD}$, was tested in cancer patients in the 1980s but did not make it beyond a phase II trial [26-31, 98]. In addition to its lack of efficacy, PALA was shown to cause DNA damage even to normal cells [99]. Whether this is due to inhibition of CAD is unknown as PALA may not be specific and, for example, PALA is a potent inhibitor of human carbonic anhydrase IV [100]. To our knowledge, various modifications of PALA have not yet rendered more effective inhibitors [101] although encapsulating PALA into liposomes may improve delivery and efficacy according to tests in mice $[102,103]$.

Thus, it is unclear as to whether CAD is not sufficiently inhibited by PALA and its analogues, or if this enzyme is not a suitable target for cancer treatment. Since CAD is a trifunctional enzyme, it is possible that blocking other enzymatic activities aside from the aspartate transcarbamoylase function may constitute a better option.

\section{DHODH inhibitors}

Mutations in DHODH cause postaxial acrofacial dysostosis or Miller syndrome [104], a rare condition with distinctive craniofacial malformations that occur in association with limb abnormalities but not with cognitive or growth problems. The DHODH inhibitor leflunomide and its active metabolite teriflunomide have long been used for chronic diseases such as rheumatoid arthritis and multiple sclerosis $[95,96]$. Thus, this suggests that targeting DHODH for cancer therapy is likely to be a safe approach. The next most advanced DHODH inhibitor with regard to clinical testing is ASLAN003 which has undergone a phase I study (https://clinicaltrials.gov/). Although the results from a phase I study with this compound are not published, ASLAN003 is now in phase II for the treatment of acute myeloid leukemia.
In the 1980s, brequinar, which still ranks as one of the most potent and selective DHODH inhibitors, was shown to work in mouse models for solid tumors as well as in a leukemia murine model [105]. Even leflunomide and teriflunomide, although weak and non-specific against DHODH, have proven efficacious in animal models [106-108]. Later on, in the early 1990s, brequinar was tested against solid tumors in patients [21-25]. Unfortunately, these trials did not demonstrate efficacy below the maximum tolerated dose.

It was not until 2016, when it was published that brequinar is a strong inducer of differentiation in acute myeloid leukemia cells, that this small molecule was brought back into the limelight [32]. Following up these studies, Bayer has started clinical trials on myeloid leukemia patients with a new and extremely potent DHODH inhibitor named BAY 2402234 [97] and other companies have followed this path (https://clinicaltrials.gov/ct2/results?cond $=\&$ term $=$ dhodh $\&$ cntry $=\&$ state $=\&$ city $=\&$ dist $=$ ). Most interestingly, brequinar is active against pancreatic cancer in xenograft studies $[109,110]$, suggesting a new way to target KRAS mutant tumors and to overcome resistance to Raf, MEK, and ERK inhibitors.

A way to increase the efficacy of DHODH inhibitors against cancer cells is to combine them with other agents. For example, inhibition of DHODH leads to activation of the p53 tumor suppressor and synergizes with inhibitors of p53 degradation ( $\mathrm{mdm} 2$ inhibitors) to kill cancer cells [33]. One explanation for this synergy between DHODH inhibitors and $\mathrm{mdm} 2$ inhibitors is that if cancer cells treated with DHODH inhibitors accumulate in S phase, releasing p53 from mdm2 at this vulnerable stage of the cell cycle may promote cell death. Another interesting feature with regard to the relationship between DHODH and p53 is that a large proportion of small molecules identified through a cell-based screen as activators of p53 can inhibit DHODH [33].

\section{UMPS inhibitors}

Pyrazofurin is an inhibitor of UMPS that acts as a nucleoside analogue and blocks the orotidine 5'monophosphate decarboxylase activity of UMPS [111]. Unfortunately, there are several difficulties in pursuing this strategy. First, it was seen that resistance to pyrazofurin was easily achieved and that this nucleoside analogue could convert into a nucleotide and potentially incorporate into nucleic acids and cause mutations [112, 113]. An alternative way to inhibit UMPS is by the use of AICAr (5-aminoimidazole-4carboxamide-1-b-riboside) whose pro-apoptotic effect, at least in the case of multiple myeloma, is thought to be mediated by the inhibition of UMPS [114]. Although the possibility of discovering other UMPS inhibitors could be considered, it may not prove to be 
safe in the clinic as loss of UMPS activity causes orotic aciduria [115].

Recently, it has been found that uric acid, a purine nucleotide degradation product abundant in human plasma, can inhibit UMPS [116]. In this regard, it may be of importance when evaluating results from preclinical tests with inhibitors of pyrimidine ribonucleotide metabolism, to remember that mouse plasma and human plasma differ significantly with regard to uric acid levels as these are 10-fold higher in the blood of humans than of mice [116].

\section{Inhibitors of uridine import}

Uridine levels in blood are not negligible [16, 43], and this could debilitate the effects of inhibitors of the de novo synthesis pathway described above. However, many inhibitors of uridine uptake are available and several are used as medicaments. Combining inhibitors of CAD, DHODH, and possibly UMPS with blockers of uridine uptake may be an attractive strategy to increase efficacy.

Uridine uptake inhibitors include dipyridamole, which inhibits ENT1 and ENT2 and is used in the clinic to prevent blood clots $[117,118]$. Surprisingly, a number of clinically approved tyrosine kinase inhibitors also block uridine uptake by cells [119]. One of the most potent ones is nilotinib [120], which is used as a Bcr-Abl inhibitor to treat chronic myeloid leukemia. Whether the inhibition of uridine uptake by nilotinib contributes to its therapeutic effect is still unknown. Nitrobenzylmercaptopurine ribonucleoside (NBMPR) has been a valuable pharmacological tool used extensively to characterize the ENT transporters [121, 122].

Since CNTs are known to more effectively transport uridine, they may constitute better targets than ENTs. However, no high affinity CNT inhibitors were available until recently. These include thienopyrimidine 2'-deoxynucleoside and ribonucleoside [43, 123]. Interestingly, the tyrosine kinase inhibitor imatinib, although not very potent $\left(\mathrm{IC}_{50}=2.3 \mu \mathrm{M}\right)$, can inhibit CNT2 [120].

The expression levels between ENTs and CNTs vary between tissues and tumor types (CCLE database). For example, CNT1 (SLC28A1) is high in the kidneys, liver, and small intestine and, accordingly, highly expressed in kidney cancers. Therefore, characterizing the specificity of small molecules for each of these nucleoside transporters may help target tumors specifically and predict toxic effects.

\section{CDA inhibitors}

Aside from ENTs and CNTs, another target of the salvage pathway is CDA, which converts cytidine into uridine and therefore, together with the CTP synthetases, regulates the ratio between uracil and cytosine nucleotides. CDA inhibitors include tetrahydrouridine [124], but also a new compound, cedazuridine (E7727), which is currently in clinical trials in combination with decitabine for the treatment of myelodysplastic syndromes and chronic myelomonocytic leukemia [125]. The rationale for this combination is that CDA inhibition will prevent deamination of decitabine and therefore increase its bioavailability. The same principle can be extended to azacitidine and cytarabine, which are also susceptible to deamination by CDA. It might be interesting to test whether altering the salvage pathway with CDA inhibitors works in synergy with inhibitors of de novo pyrimidine ribonucleotide synthesis.

\section{CTPS I and II inhibitors}

CTP synthetase activity, which converts UTP into CTP, may be upregulated in tumors according to a study performed decades ago [126]. CTP synthetases form remarkable structures in cells called cytoophidia due to their snake-like shape that are present in the cytoplasm as well as in the nucleus [127]. In humans, CTPS polymerization increases catalytic activity [128] and CTPS activity may be regulated by post-translational modifications or binding to other factors [129]. CTPS filaments assemble at particular developmental stages (e.g., when there is a high demand for CTP) as well as in response to nutrient stress. Indeed, CTPS filaments form in response to glutamine deprivation and disassemble upon glutamine addition to cells $[128,130]$. An intriguing question is why active hCTPS forms polymers? In this regard, it is interesting that in S. pombe cells, CTPS cytoophidia are asymmetrically inherited during cell division and in a stochastic fashion [131]. Therefore, agents that affect cytoophidia formation on dividing cells may influence the distribution of this CTP synthetase enzymatic activity between daughter cells and, in this manner, affect the proliferation potential of at least one of the daughter cells. Agents that directly affect CTP synthetases include cyclopentenyl cytosine (CPEC), but whether this is a safe anticancer strategy needs to be established as cardiotoxicity has been reported in a phase I trial [132]. In addition, accumulation of UTP might lead to nucleotide imbalance as well as to high dUTP levels.

\section{DPYD inhibitors}

DPYD is involved in the degradation of uracil, and therefore, its inhibition could lead to an increase in UMP levels (Fig. 1). This enzyme can be inhibited by gimeracil and eniluracil, which were designed to improve the efficacy of 5-fluorouracil by decreasing its breakdown by DPYD. Eniluracil failed in phase III trials, but gimeracil is still in clinical trials (https://clinicaltrials.gov). 
One question that could be worth investigating is whether these inhibitors also affect the efficacy of UMP synthesis inhibitors. In principle, inhibition of DPYD would be expected to rescue UMP from degradation and therefore weaken the efficacy of inhibitors of de novo pyrimidine ribonucleotide synthesis. If this occurs, one could speculate that tumors that express high levels of DPYD would be more sensitive to UMP synthesis inhibitors.

\section{Conclusions}

The recent advances in the identification of small molecule modulators of pyrimidine ribonucleotide synthesis, and in particular of small molecule inhibitors of $\mathrm{DHODH}$, have led to a renewed interest in this field of research for the treatment of cancer. If the current clinical trials with DHODH inhibitors on leukemia patients show signs of efficacy and low toxicity, the next challenge will be to find synergistic and safe combinations with other agents and to extend the use of pyrimidine ribonucleotide synthesis inhibitors to patients with solid tumors. Bearing in mind the failure of the CAD inhibitor PALA and the DHODH inhibitor brequinar in clinical trials for solid tumors in the 1990s, it is not unreasonable to postulate that identifying molecular signatures in cancer cells that confer hypersensitivity to depletion of pyrimidine ribonucleotide pools will be crucial. Considering the effects of food intake on uridine levels may also be key to improve efficacy. In addition, given the importance of the immune system in the prevention of cancer, the immunosuppressive effect of ribonucleotide synthesis inhibitors must be taken into account.

\footnotetext{
Abbreviations

ADP: Adenosine 5'-diphosphate; ATP: Adenosine 5'-triphosphate; $\beta$-ala: $\beta$ Alanine; CAD: Carbamoylphosphate synthetase II, aspartate transcarbamoylase, and dihydroorotase; CDA: Cytidine deaminase; CDP: Cytidine 5'-diphosphate; CDP-PL: CDP-linked phospholipids; CMP: Cytidine 5'-monophosphate; CNT: Concentrative nucleoside transporter; Ctd: Cytidine; CPSII: Carbamoylphosphate synthetase II; CTP: Cytidine 5'triphosphate; CTPS I: Cytidine 5'-triphosphate synthetase I; CTPS II: Cytidine 5'-triphosphate synthetase II; dCDP: 2'-Deoxycytidine 5'-diphosphate; dCMP: 2'-Deoxycytidine 5'-monophosphate; dCtd: Deoxycytidine; DHOA: Dihydroorotic acid; DHODH: Dihydroorotate dehydrogenase; DPYD: Dihydropyrimidine dehydrogenase; dTMP: 2'-Deoxythymidine-5'monophosphate; dTTP: 2'-Deoxythymidine-5'-triphosphate; dUMP: 2'Deoxyuridine 5'-monophosphate; dUrd: Deoxyuridine; dUTP: 2'-Deoxyuridine5'-triphosphate; ENT: Equilibrative nucleoside transporter; hCTPS I: Human cytidine 5'-triphosphate synthetase I; L-Asp: L-Aspartate; L-GIn: L-Glutamine; MAPK: Mitogen-activated protein kinase; OA: Orotic acid; PALA: NPhosphonacetyl-L-aspartate; PKA: Cyclic adenosine monophosphatedependent protein kinase; PKC: Protein kinase C; PRPP: Phosphoribosyl pyrophosphate; RNR: Ribonucleotide reductase; Thd: Thymidine; UDP: Uridine 5'-diphosphate; UMP: Uridine 5'-monophosphate; UMPS: Uridine monophosphate synthetase; UTP: Uridine 5'-triphosphate; Ura: Uracil; Urd: Uridine
}

\section{Acknowledgements}

Not applicable

\section{Authors' contributions}

TM and SL did the literature search, wrote the manuscript, and prepared the figure. The authors read and approved the final manuscript.

\section{Funding}

Project grants from the Swedish Research Council, the Swedish Cancer Society, and the Swedish Childhood Cancer Foundation. Open access funding provided by Karolinska Institute.

\section{Availability of data and materials}

Not applicable

Ethics approval and consent to participate

Not applicable

\section{Consent for publication}

Not applicable

\section{Competing interests}

$\mathrm{SL}$ has filed a patent application on the use of a novel class of $\mathrm{DHODH}$ inhibitors for cancer treatment. TM declares no competing interests.

Received: 19 September 2019 Accepted: 14 May 2020

Published online: 09 June 2020

\section{References}

1. Evans DR, Guy HI. Mammalian pyrimidine biosynthesis: fresh insights into an ancient pathway. J Biol Chem. 2004;279(32):33035-8.

2. Jones ME. Pyrimidine nucleotide biosynthesis in animals: genes, enzymes, and regulation of UMP biosynthesis. Annu Rev Biochem. 1980;49:253-79.

3. Traut TW. Physiological concentrations of purines and pyrimidines. Mol Cell Biochem. 1994;140(1):1-22.

4. Loffler M, Fairbanks LD, Zameitat E, Marinaki AM, Simmonds HA. Pyrimidine pathways in health and disease. Trends Mol Med. 2005;11(9):430-7.

5. Jacobson K, Costanzi S, Ohno M, Joshi B, Besada P, Xu B, et al. Molecular recognition at purine and pyrimidine nucleotide $(\mathrm{P} 2)$ receptors. Curr Top Med Chem. 2004;4(8):805-19.

6. Communi D, Boeynaems J-M. Receptors responsive to extracellular pyrimidine nucleotides. Trends Pharmacol Sci. 1997;18(3):83-6.

7. Seifert R. CCMP and CUMP: emerging second messengers. Trends Biochem Sci. 2015;40(1):8-15.

8. Wolter S, Golombek M, Seifert R. Differential activation of CAMP- and CGMPdependent protein kinases by cyclic purine and pyrimidine nucleotides. Biochem Biophys Res Commun. 2011;415(4):563-6.

9. Levine RL, Hoogenraad NJ, Kretchmer N. A review: biological and clinical aspects of pyrimidine metabolism. Pediatr Res. 1974;8(7):724-34.

10. Ito K, Uchino $\mathrm{H}$. Control of pyrimidine biosynthesis in human lymphocytes. Induction of glutamine-utilizing carbamyl phosphate synthetase and operation of orotic acid pathway during blastogenesis. J Biol Chem. 1971; 246(12):4060-5

11. Roux JM, Hoogenraad NJ, Kretchmer N. Biosynthesis of pyrimidine nucleotides in mouse salivary glands stimulated with isoproterenol. J Biol Chem. 1973;248(4):1196-202.

12. Clark ML, Senior JR. Small gut mucosal activities of pyrimidine precursor enzymes in celiac disease. Gastroenterology. 1969;56(5):887-94.

13. Galofré A, Kretchmer N. Biosynthesis of pyrimidines by various organs of the chick during embryogenesis. Pediatr Res. 1970;4:55.

14. Young JE, Prager MD, Atkins IC. Comparative activties of aspartate transcarbamylase in various tissues of the rat. Proc Soc Exp Biol Med. 1967; 125(3):860-2.

15. Berg AA, Lenthe $H$, Busch $S$, Korte $D$, Roos D. Kuilenburg ABP, et al. Evidence for transformation-related increase in CTP synthetase activity in situ in human lymphoblastic leukemia. 1993;216(1):161-7.

16. Volm M, Zintl F, Sauerbrey A. Thymidylate synthase in childhood acute nonlymphoblastic leukemia. Anticancer Res. 1994;14(3b):1271-5.

17. Collart FR, Chubb CB, Mirkin BL, Huberman E. Increased inosine-5'phosphate dehydrogenase gene expression in solid tumor tissues and tumor cell lines. Cancer Res. 1992;52(20):5826-8.

18. Weber G. Enzymes of purine metabolism in cancer. Clin Biochem. 1983; 16(1):57-63. 
19. Calva E, Lowenstein JM, Cohen PP. Carbamyl phosphate-aspartate transcarbamylase activity in tumors. Cancer Res. 1959;19(1):101.

20. Bresnick E, Mainigi KD, Mayfield ED, Morris HP. Activities of enzymes of pyrimidine nucleotide synthesis in slowly growing kidney tumors. Cancer Res. 1969;29(11):1932.

21. Urba S, Doroshow J, Cripps C, Robert F, Velez-Garcia E, Dallaire B, et al. Multicenter phase II trial of brequinar sodium in patients with advanced squamous-cell carcinoma of the head and neck. Cancer Chemother Pharmacol. 1992;31(2):167-9.

22. Natale R, Wheeler R, Moore M, Dallaire B, Lynch W, Carlson R, et al. Multicenter phase II trial of brequinar sodium in patients with advanced melanoma. Ann Oncol. 1992;3(8):659-60.

23. Moore M, Maroun J, Robert F, Natale R, Neidhart J, Dallaire B, et al. Multicenter phase II study of brequinar sodium in patients with advanced gastrointestinal cancer. Invest New Drugs. 1993;11(1):61-5.

24. Maroun J, Ruckdeschel J, Natale R, Morgan R, Dallaire B, Sisk R, et al. Multicenter phase II study of brequinar sodium in patients with advanced lung cancer. Cancer Chemother Pharmacol. 1993;32(1):64-6.

25. Cody R, Stewart D, DeForni M, Moore M, Dallaire B, Azarnia N, et al. Multicenter phase $\|$ study of brequinar sodium in patients with advanced breast cancer. Am J Clin Oncol. 1993;16(6):526-8.

26. Taylor GS, Davis ET, Falkson MG, Keller MA. PALA in advanced breast cancer A phase II pilot study by the ECOG. Am J Clin Oncol. 1982;5(6):627-30.

27. Muss BH, Bundy JB, Disaia BP, Stehman BF, Beecham BJ. PALA (NSC-224131) in advanced carcinoma of the cervix: a phase II study of the Gynecologic Oncology Group. Am J Clin Oncol. 1984;7(6):741-4.

28. Carroll DS, Gralla RJ, Kemeny NE. Phase II evaluation of N-phosphonacetyl-Laspartic acid (PALA) in patients with advanced colorectal carcinoma. Cancer Treat Rep. 1980;64(2-3):349

29. Muggia FM, Tsiatis AA, O'Connell MJ, Glick JH, Opfell RW, Coren A. Phase II trial of PALA in lymphoma: an Eastern Cooperative Oncology Group study. Cancer Treat Rep. 1984;68(3):551.

30. Kleeberg UR, Mulder JH, Rümke P, Thomas D, Rozencweig M. N(Phosphonacetyl)- I-aspartate (PALA) in advanced malignant melanoma: a phase II trial of the EORTC malignant melanoma cooperative group. Eur J Cancer Clin Oncol. 1982;18(8):723-6.

31. Kurzrock SR, Yap PB-S, Plager PC, Papdopoulos PN, Benjamin PR, Valdivieso PM, et al. Phase II evaluation of PALA in patients with refractory metastatic sarcomas. Am J Clin Oncol. 1984;7(4):305-8.

32. Sykes DB, Kfoury YS, Mercier FE, Wawer MJ, Law JM, Haynes MK, et al. Inhibition of dihydroorotate dehydrogenase overcomes differentiation blockade in acute myeloid leukemia. Cell. 2016;167(1):171-86.e15.

33. Ladds M, van Leeuwen IMM, Drummond CJ, Chu S, Healy AR, Popova G, et al. A DHODH inhibitor increases p53 synthesis and enhances tumor cell killing by p53 degradation blockage. Nat Commun. 2018;9(1):2071.

34. Lewis TA, Sykes DB, Law JM, Muñoz B, Rustiguel JK, Nonato MC, et al. Development of ML390: a human DHODH inhibitor that induces differentiation in acute myeloid leukemia. ACS Med Chem Lett. 2016;7(12):1112-7.

35. DeBerardinis RJ, Cheng T. Q's next: the diverse functions of glutamine in metabolism, cell biology and cancer. Oncogene. 2009;29:313.

36. Connolly GP, Duley JA. Uridine and its nucleotides: biological actions, therapeutic potentials. Trends Pharmacol Sci. 1999;20(5):218-25.

37. Huang M, Graves LM. De novo synthesis of pyrimidine nucleotides: emerging interfaces with signal transduction pathways. Cell Mol Life Sci. 2003;60(2):321-36.

38. Vance JE, Vance DE. Phospholipid biosynthesis in mammalian cells. Biochemistry and cell biology = Biochimie et biologie cellulaire. 2004;82(1):113-28.

39. Friedberg EC, Walkker GC, Siede W, Wood RD, Schultz RA, Ellenberger T. DNA Repair and Mutagenesis. 2nd ed. Washington DC: ASM Press; 2006.

40. Tomasetti C, Li L, Vogelstein B. Stem cell divisions, somatic mutations, cancer etiology, and cancer prevention. Sci. 2017;355(6331):1330-4.

41. Becroft DM, Phillips LI, Simmonds A. Hereditary orotic aciduria: long-term therapy with uridine and a trial of uracil. J Pediatr. 1969;75(5):885-91.

42. Tavazzi B, Lazzarino G, Leone P, Amorini AM, Bellia F, Janson CG, et al. Simultaneous high performance liquid chromatographic separation of purines, pyrimidines, $\mathrm{N}$-acetylated amino acids, and dicarboxylic acids for the chemical diagnosis of inborn errors of metabolism. Clin Biochem. 2005; 38(11):997-1008

43. Young JD, Yao SY, Baldwin JM, Cass CE, Baldwin SA. The human concentrative and equilibrative nucleoside transporter families, SLC28 and SLC29. Mol Aspects Med. 2013;34(2-3):529-47.
44. Young JD, Yao SY, Sun L, Cass CE, Baldwin SA. Human equilibrative nucleoside transporter (ENT) family of nucleoside and nucleobase transporter proteins. Xenobiotica; the fate of foreign compounds in biological systems. 2008;38(7-8):995-1021.

45. Pastor-Anglada M, Pérez-Torras S. Nucleoside transporter proteins as biomarkers of drug responsiveness and drug targets. Front Pharmacol. 2015; 6:13.

46. Damaraju VL, Damaraju S, Young JD, Baldwin SA, Mackey J, Sawyer MB, et al. Nucleoside anticancer drugs: the role of nucleoside transporters in resistance to cancer chemotherapy. Oncogene. 2003;22(47):7524-36.

47. Boswell-Casteel RC, Hays FA. Equilibrative nucleoside transporters-a review. Nucleosides Nucleotides Nucleic Acids. 2017;36(1):7-30.

48. Molina-Arcas M, Casado FJ, Pastor-Anglada M. Nucleoside transporter proteins. Curr Vasc Pharmacol. 2009;7(4):426-34.

49. Zhou M, Xia L, Engel K, Wang J. Molecular determinants of substrate selectivity of a novel organic cation transporter (PMAT) in the SLC29 family. J Biol Chem. 2007;282(5):3188-95.

50. Rodraguez-Mulero S, Errasti-Murugarren E, Ballaran J, Felipe A, Doucet A, Casado $\mathrm{F}$, et al. Expression of concentrative nucleoside transporters SLC28 (CNT1, CNT2, and CNT3) along the rat nephron: effect of diabetes. Kidney Int. 2005;68(2):665-72.

51. Smith KM, Ng AML, Yao SYM, Labedz KA, Knaus EE, Wiebe LI, et al. Electrophysiological characterization of a recombinant human $\mathrm{Na}$ +-coupled nucleoside transporter (hCNT1) produced in Xenopus oocytes. J Physiol. 2004;558(3):807-23.

52. Goetz U, Da Prada M, Pletscher A. Adenine-, guanine- and uridine-5'phosphonucleotides in blood platelets and storage organelles of various species. J Pharmacol Exp Ther. 1971;178(1):210-5.

53. Berman P, Harley E. Orotate uptake and metabolism by human erythrocytes. Adv Exp Med Biol. 1984;165(Pt A):367-71.

54. Deng Y, Wang ZV, Gordillo R, An Y, Zhang C, Liang Q, et al. An adipo-biliaryuridine axis that regulates energy homeostasis. Science (New York, NY). 2017;355(6330):eaaf5375

55. Teruya T, Chaleckis R, Takada J, Yanagida M, Kondoh H. Diverse metabolic reactions activated during 58-hr fasting are revealed by non-targeted metabolomic analysis of human blood. Sci Rep. 2019;9(1):854

56. Henricks LM, Jacobs BAW, Meulendijks D, Pluim D, van den Broek D, de Vries $\mathrm{N}$, et al. Food-effect study on uracil and dihydrouracil plasma levels as marker for dihydropyrimidine dehydrogenase activity in human volunteers. Br J Clin Pharmacol. 2018;84(12):2761-9.

57. Jacobs BA, Deenen MJ, Pluim D, van Hasselt JG, Krahenbuhl MD, van Geel RM, et al. Pronounced between-subject and circadian variability in thymidylate synthase and dihydropyrimidine dehydrogenase enzyme activity in human volunteers. Br J Clin Pharmacol. 2016;82(3):706-16.

58. van Groeningen CJ, Peters GJ, Nadal JC, Laurensse E, Pinedo HM. Clinical and pharmacologic study of orally administered uridine. J Natl Cancer Inst. 1991;83(6):437-41.

59. Kelsen DP, Martin D, O'Neil J, Schwartz G, Saltz L, Sung MT, et al. Phase I trial of PN401, an oral prodrug of uridine, to prevent toxicity from fluorouracil in patients with advanced cancer. J Clin Oncol. 1997;15(4):1511-7.

60. Steculorum SM, Paeger L, Bremser S, Evers N, Hinze $Y$, Idzko M, et al. Hypothalamic UDP increases in obesity and promotes feeding via P2Y6dependent activation of AgRP neurons. Cell. 2015;162(6):1404-17.

61. Sugiyama E, Kaniwa N, Kim S-R, Kikura-Hanajiri R, Hasegawa R, Maekawa K, et al. Pharmacokinetics of gemcitabine in Japanese cancer patients: the impact of a cytidine deaminase polymorphism. J Clin Oncol. 2006;25(1):32-42.

62. Lamba JK. Genetic factors influencing cytarabine therapy. Pharmacogenomics. 2009;10(10):1657-74.

63. Deenen MJ, Meulendijks D, Cats A, Sechterberger MK, Severens JL, Boot H, et al. Upfront genotyping of DPYD*2A to individualize fluoropyrimidine therapy: a safety and cost analysis. J Clin Oncol. 2015;34(3):227-34

64. Lane AN, Fan TWM. Regulation of mammalian nucleotide metabolism and biosynthesis. Nucleic Acids Res. 2015;43(4):2466-85.

65. Miltenberger RJ, Sukow KA, Farnham PJ. An E-box-mediated increase in cad transcription at the G1/S-phase boundary is suppressed by inhibitory c-Myc mutants. Mol Cell Biol. 1995;15(5):2527.

66. Boyd KE, Farnham PJ. Myc versus USF: discrimination at the cad gene is determined by core promoter elements. Mol Cell Biol. 1997;17(5):2529.

67. Liu Y-C, Li F, Handler J, Huang CRL, Xiang Y, Neretti N, et al. Global regulation of nucleotide biosynthetic genes by c-Myc. PLoS One. 2008; 3(7):e2722. 
68. Khan S, Abdelrahim M, Samudio I, Safe S. Estrogen receptor/Sp1 complexes are required for induction of cad gene expression by 17 beta-estradiol in breast cancer cells. Endocrinology. 2003;144(6):2325-35.

69. Chen K-F, Lai Y-Y, Sun HS, Tsai S-J. Transcriptional repression of human cad gene by hypoxia inducible factor-1a. Nucleic Acids Res. 2005;33(16):5190-8.

70. Tatibana M, Shigesada K. Two carbamyl phosphate synthetases of mammals: specific roles in control of pyrimidine and urea biosynthesis. Adv Enzyme Regul. 1972;10:249.

71. Rubio V, Cervera J, Lusty CJ, Bendala E, Britton HG. Domain structure of the large subunit of Escherichia coli carbamoyl phosphate synthetase. Location of the binding site for the allosteric inhibitor UMP in the carboxy-terminal domain. Biochemistry. 1991;30(4):1068-75.

72. Jones ME. Regulation of pyrimidine and arginine biosynthesis in mammals. Adv Enzyme Regul. 1971;9:19-49.

73. Sigoillot FD, Evans DR, Guy HI. Growth-dependent regulation of mammalian pyrimidine biosynthesis by the protein kinase A and MAPK signaling cascades. J Biol Chem. 2002;277(18):15745-51.

74. Graves LM, Guy HI, Kozlowski P, Huang M, Lazarowski E, Pope RM, et al. Regulation of carbamoyl phosphate synthetase by MAP kinase. Nature. 2000;403:328.

75. Kotsis DH, Masko EM, Sigoillot FD, Gregorio RD, Guy-Evans HI, Evans DR. Protein kinase A phosphorylation of the multifunctional protein CAD antagonizes activation by the MAP kinase cascade. Mol Cell Biochem. 2007; 301(1):69-81.

76. Carrey EA, Campbell DG, Hardie DG. Phosphorylation and activation of hamster carbamyl phosphate synthetase II by CAMP-dependent protein kinase. A novel mechanism for regulation of pyrimidine nucleotide biosynthesis. EMBO J. 1985;4(13b):3735-42.

77. Sigoillot FD, Berkowski JA, Sigoillot SM, Kotsis DH, Guy HI. Cell cycledependent regulation of pyrimidine biosynthesis. J Biol Chem. 2003;278(5): 3403-9.

78. Sigoillot FD, Kotsis DH, Masko EM, Bame M, Evans DR, Evans HI. Protein kinase $C$ modulates the up-regulation of the pyrimidine biosynthetic complex, CAD, by MAP kinase. Front Biosci. 2007;12:3892-8.

79. Sigoillot FD, Sigoillot SM, Guy HI. Breakdown of the regulatory control of pyrimidine biosynthesis in human breast cancer cells. Int J Cancer. 2004; 109(4):491-8.

80. Little Annette S, Balmanno K, Sale Matthew J, Smith Paul D, Cook SJ. Tumour cell responses to MEK1/2 inhibitors: acquired resistance and pathway remodelling. Biochem Soc Trans. 2012;40(1):73.

81. Wagle N, Emery C, Berger MF, Davis MJ, Sawyer A, Pochanard P, et al. Dissecting therapeutic resistance to RAF inhibition in melanoma by tumor genomic profiling. J Clin Oncol. 2011;29(22):3085-96.

82. Liu F, Yang X, Geng M, Huang M. Targeting ERK, an Achilles' Heel of the MAPK pathway, in cancer therapy. Acta pharmaceutica Sinica B. 2018;8(4): 552-62.

83. Jha S, Morris EJ, Hruza A, Mansueto MS, Schroeder GK, Arbanas J, et al. Dissecting therapeutic resistance to ERK inhibition. Mol Cancer Ther. 2016; 15(4):548-59.

84. Robitaille AM, Christen S, Shimobayashi M, Cornu M, Fava LL, Moes S, et al. Quantitative phosphoproteomics reveal mTORC1 activates de novo pyrimidine synthesis. Science (New York, NY). 2013;339(6125): 1320.

85. Ben-Sahra I, Howell JJ, Asara JM, Manning BD. Stimulation of de novo pyrimidine synthesis by growth signaling through mTOR and S6K1. Science (New York, NY). 2013;339(6125):1323.

86. Faes $\mathrm{S}$, Demartines $\mathrm{N}$, Dormond O. Resistance to mTORC1 inhibitors in cancer therapy: from kinase mutations to intratumoral heterogeneity of kinase activity. Oxid Med Cell Longev. 2017;2017:10.

87. Shimobayashi M, Hall MN. Making new contacts: the mTOR network in metabolism and signalling crosstalk. Nat Rev Mol Cell Biol. 2014;15:155.

88. Ben-Sahra I, Manning BD. mTORC1 signaling and the metabolic control of cell growth. Curr Opin Cell Biol. 2017;45:72-82.

89. Sato T, Akasu H, Shimono W, Matsu C, Fujiwara Y, Shibagaki Y, et al. Rheb protein binds CAD (carbamoyl-phosphate synthetase 2, aspartate transcarbamoylase, and dihydroorotase) protein in a GTP- and effector domain-dependent manner and influences its cellular localization and carbamoyl-phosphate synthetase (CPSase) activity. J Biol Chem. 2015;290(2): 1096-105.

90. Ilagan E, Manning BD. Emerging role of $m T O R$ in the response to cancer therapeutics. Trends in Cancer. 2016;2(5):241-51.
91. Inoki K, Corradetti MN, Guan K-L. Dysregulation of the TSC-mTOR pathway in human disease. Nat Genet. 2004;37:19.

92. Menon S, Manning BD. Common corruption of the mTOR signaling network in human tumors. Oncogene. 2009;27:S43.

93. Pallet $\mathrm{N}$, Legendre C. Adverse events associated with mTOR inhibitors. Expert Opin Drug Saf. 2013;12(2):177-86.

94. Linke SP, Clarkin KC, Di Leonardo A, Tsou A, Wahl GM. A reversible, p53dependent G0/G1 cell cycle arrest induced by ribonucleotide depletion in the absence of detectable DNA damage. Genes Dev. 1996;10(8):934-47.

95. Haghikia A, Gold R. TOWER confirms the efficacy of oral teriflunomide in MS. Nat Rev Neurol. 2014;10:183.

96. Kasarełło K, Cudnoch-Jędrzejewska A, Członkowski A, Mirowska-Guzel D. Mechanism of action of three newly registered drugs for multiple sclerosis treatment. Pharmacol Rep. 2017;69(4):702-8.

97. Christian S, Merz C, Evans L, Gradl S, Seidel H, Friberg A, et al. The novel dihydroorotate dehydrogenase (DHODH) inhibitor BAY 2402234 triggers differentiation and is effective in the treatment of myeloid malignancies. Leukemia. 2019; 33(10):2403-15.

98. Grem JL, King SA, O'Dwyer PJ, Leyland-Jones B. Biochemistry and clinical activity of N-(phosphonacetyl)-L-aspartate: a review. Cancer Res. 1988;48(16): 4441-54.

99. Hastak K, Paul RK, Agarwal MK, Thakur VS, Amin AR, Agrawal S, et al. DNA synthesis from unbalanced nucleotide pools causes limited DNA damage that triggers ATR-CHK1-dependent p53 activation. Proc Natl Acad Sci U S A. 2008;105(17):6314-9.

100. Winum JY, Innocenti A, Gagnard V, Montero JL, Scozzafava A, Vullo D, et al. Carbonic anhydrase inhibitors. Interaction of isozymes I, II, IV, V, and IX with organic phosphates and phosphonates. Bioorg Med Chem Lett. 2005;15(6): 1683-6.

101. Coudray L, Pennebaker AF, Montchamp JL. Synthesis and in vitro evaluation of aspartate transcarbamoylase inhibitors. Bioorg Med Chem. 2009;17(22): 7680-9.

102. Kim J-S, Heath TD. Antitumor efficacy of liposomal N-(phosphonacetyl)-Laspartic acid in C-26 tumor bearing Balb/c mice. J Pharm Investig. 2000; 30(1):39-45

103. Kim J-S, Heath TD. Therapeutic potency of N-(Phosphonacetyl)-L-Aspartic Acid in liposome in established tumor bearing mice. J Pharm Investig. 2000; 30(2):127-31.

104. Ng SB, Buckingham K, Lee C, Bigham AW, Tabor HK, Dent KM, et al. Exome sequencing identifies the cause of a mendelian disorder. Nat Genet. 2010; 42(1):30-5.

105. Dexter DL, Hesson DP, Ardecky RJ, Rao GV, Tippett DL, Dusak BA, et al. Activity of a novel 4-quinolinecarboxylic acid, NSC 368390 [6-fluoro-2-(2'fluoro-1,1'-biphenyl-4-yl)-3-methyl-4-quinolinecarb oxylic acid sodium salt], against experimental tumors. Cancer Res. 1985;45(11 Pt 1):5563-8.

106. Brown KK, Spinelli JB, Asara JM, Toker A. Adaptive reprogramming of de novo pyrimidine synthesis is a metabolic vulnerability in triple-negative breast cancer. Cancer Discov. 2017;7(4):391-9.

107. Mathur D, Stratikopoulos E, Ozturk S, Steinbach N, Pegno S, Schoenfeld $S$, et al. PTEN regulates glutamine flux to pyrimidine synthesis and sensitivity to dihydroorotate dehydrogenase inhibition. Cancer Discov. 2017;7(4):380-90.

108. White RM, Cech J, Ratanasirintrawoot S, Lin CY, Rahl PB, Burke CJ, et al. $\mathrm{DHODH}$ modulates transcriptional elongation in the neural crest and melanoma. Nature. 2011;471(7339):518-22.

109. Koundinya M, Sudhalter J, Courjaud A, Lionne B, Touyer G, Bonnet L, et al. Dependence on the pyrimidine biosynthetic enzyme $\mathrm{DHODH}$ is a synthetic lethal vulnerability in mutant KRAS-driven cancers. Cell chemical biology. 2018;25(6):705-17.e11.

110. Santana-Codina N, Roeth AA, Zhang Y, Yang A, Mashadova O, Asara JM, et al. Oncogenic KRAS supports pancreatic cancer through regulation of nucleotide synthesis. Nat Commun. 2018;9(1):4945.

111. Huang H-S, Wang R, Chen W-J, Chen J-Z, Gong S-S, Sun Q. The first chemical synthesis of pyrazofurin $5^{\prime}$-triphosphate. Tetrahedron Lett. 2018; 59(37):3423-7.

112. Dix DE, Lehman CP, Jakubowski A, Moyer JD, Handschumacher RE. Pyrazofurin metabolism, enzyme inhibition, and resistance in L5178Y cells. Cancer Res. 1979;39(11):4485-90.

113. Ringer DP, Howell BA, Etheredge JL. Alteration in de novo pyrimidine biosynthesis during uridine reversal of pyrazofurin-inhibited dna synthesis. J Biochem Toxicol. 1991;6(1):19-27. 
114. Bardeleben C, Sharma S, Reeve JR, Bassilian S, Frost P, Hoang B, et al. Metabolomics identifies pyrimidine starvation as the mechanism of 5aminoimidazole-4-carboxamide-1- $\beta$-riboside-induced apoptosis in multiple myeloma cells. Mol Cancer Ther. 2013;12(7):1310-21.

115. Suchi M, Mizuno H, Kawai Y, Tsuboi T, Sumi S, Okajima K, et al. Molecular cloning of the human UMP synthase gene and characterization of point mutations in two hereditary orotic aciduria families. Am J Hum Genet. 1997; 60(3):525-39.

116. Cantor JR, Abu-Remaileh M, Kanarek N, Freinkman E, Gao X, Louissaint A et al. Physiologic medium rewires cellular metabolism and reveals uric acid as an endogenous inhibitor of UMP synthase. Cell. 2017;169(2):258-72.e17.

117. Griffiths M, Beaumont N, Yao SYM, Sundaram M, Boumah CE, Davies A, et al. Cloning of a human nucleoside transporter implicated in the cellular uptake of adenosine and chemotherapeutic drugs. Nat Med. 1997;3(1):89-93.

118. Crawford CR, Patel DH, Naeve C, Belt JA. Cloning of the human equilibrative, nitrobenzylmercaptopurine riboside (NBMPR)-insensitive nucleoside transporter ei by functional expression in a transport-deficient cell line. J Biol Chem. 1998;273(9):5288-93.

119. Huang M, Wang Y, Cogut SB, Mitchell BS, Graves LM. Inhibition of nucleoside transport by protein kinase inhibitors. J Pharmacol Exp Ther. 2003;304(2):753-60.

120. Damaraju VL, Weber D, Kuzma M, Cass CE, Sawyer MB. Selective inhibition of human equilibrative and concentrative nucleoside transporters by bcr-abl kinase Inhibitors: identification of key hent1 amino acid residues for interaction with bcr-abl kinase inhibitors. J Biol Chem. 2016;291(36):18809-17.

121. King AE, Ackley MA, Cass CE, Young JD, Baldwin SA. Nucleoside transporters: from scavengers to novel therapeutic targets. Trends Pharmacol Sci. 2006;27(8):416-25.

122. Zhang J, Visser F, King KM, Baldwin SA, Young JD, Cass CE. The role of nucleoside transporters in cancer chemotherapy with nucleoside drugs. Cancer Metastasis Rev. 2007;26(1):85-110.

123. Damaraju VL, Smith KM, Mowles D, Nowak I, Karpinski E, Young JD, et al. Interaction of fused-pyrimidine nucleoside analogs with human concentrative nucleoside transporters: high-affinity inhibitors of human concentrative nucleoside transporter 1. Biochem Pharmacol. 2011;81(1):82-90.

124. Chabner BA, Johns DG, Coleman CN, Drake JC, Evans WH. Purification and properties of cytidine deaminase from normal and leukemic granulocytes. J Clin Invest. 1974;53(3):922-31.

125. Garcia-Manero G, Odenike O, Amrein PC, Steensma DP, DeZern AE, Michaelis LC, et al. Successful emulation of IV decitabine pharmacokinetics with an oral fixed-dose combination of the oral cytidine deaminase inhibitor (CDAi) E7727 with oral decitabine, in subjects with myelodysplastic syndromes (MDS): final data of phase 1 study. Blood. 2016;128(22):114

126. Kizaki H, Williams JC, Morris HP, Weber G. Increased cytidine 5'-triphosphate synthetase activity in rat and human tumors. Cancer Res. 1980;40(11):39217.

127. Gou KM, Chang CC, Shen QJ, Sung LY, Liu JL. CTP synthase forms cytoophidia in the cytoplasm and nucleus. Exp Cell Res. 2014;323(1):242-53.

128. Lynch EM, Hicks DR, Shepherd M, Endrizzi JA, Maker A, Hansen JM, et al. Human CTP synthase filament structure reveals the active enzyme conformation. Nat Struct Mol Biol. 2017;24(6):507-14.

129. Higgins MJ, Loiselle D, Haystead TA, Graves LM. Human cytidine triphosphate synthetase 1 interacting proteins. Nucleosides Nucleotides Nucleic Acids. 2008;27(6):850-7.

130. Calise SJ, Carcamo WC, Krueger C, Yin JD, Purich DL, Chan EK. Glutamine deprivation initiates reversible assembly of mammalian rods and rings. Cell Mol life Sci. 2014;71(15):2963-73.

131. Zhang J, Hulme L, Liu JL. Asymmetric inheritance of cytoophidia in Schizosaccharomyces pombe. Biology open. 2014;3(11):1092-7.

132. Schimmel K, Gelderblom H, Guchelaar HJ. Cyclopentenyl cytosine (CPEC): an overview of its in vitro and in vivo activity. Curr Cancer Drug Targets. 2007;7(5):504-9.

\section{Publisher's Note}

Springer Nature remains neutral with regard to jurisdictional claims in published maps and institutional affiliations.

\section{Ready to submit your research? Choose BMC and benefit from:}

- fast, convenient online submission

- thorough peer review by experienced researchers in your field

- rapid publication on acceptance

- support for research data, including large and complex data types

- gold Open Access which fosters wider collaboration and increased citations

- maximum visibility for your research: over $100 \mathrm{M}$ website views per year

At BMC, research is always in progress.

Learn more biomedcentral.com/submissions 